\title{
IbM PELATIHAN DESAIN LABEL MAKANAN OLAHAN PADA SENTRA MAKANAN KECIL DI KELURAHAN TANJUNG
}

\author{
Herni Justiana Astuti \\ Universitas Muhammadiyah Purwokerto \\ Fatmah Bagis \\ Universitas Muhammadiyah Purwokerto \\ Maharani Retnaningrum \\ Universitas Muhammadiyah Purwokerto
}

\begin{abstract}
The aims of this IbM event are to give skill and knowledge about design and labelling food and beverage. The IbM was organized on food UMKM in Tanjung in which has 28 person. This event was performed by an economic and business faculty team of Muhammadiyah University of Purwokerto. The results of this IbM events is added knowledge and skill value about interested design and labelling of food and beverage and also added economic value of those product.
\end{abstract}

Keyword : IbM, design, labelling, food and beverage, economic value

\section{Abstrak}

Kegiatan IbM ini bertujuan untuk memberikan tambahan keterampilan dan pengetahuan mengenai desain label kemasan makanan dan minuman. IbM dilakukan pada mitra UMKM makanan olahan di Kelurahan Tanjung yang beranggotakan 28 orang. Kegiatan ini dilakukan oleh tim pelaksana dari fakultas ekonomi dan bisnis Universitas Muhammadiyah Purwokerto. Hasil dari kegiatan ini adalah kelompok mitra memiliki tambahan pengetahuan dan ketrampilan dalam mendesain label makanan yang menarik untuk menambah nilai ekonomis dari produk yang telah mitra produksi

Kata kunci : IbM, desain, label, makanan, nilai ekonomis

\section{PENDAHULUAN}

Banyumas memiliki 1,7 jiwa penduduk dimana $50 \%$ masyarakatnya bergerak di bidang UMKM (dindukcapil.banyumaskab.go.id), kegiatan UMKM tersebut sangat membantu peran pemerintah dalam rangka menekan kemiskinan dan pengangguran. Salah satu upaya memajukan UMKM di Kabupaten Banyumas ditempuh dengan adanya kegiatan pelatihan, pembinaan, promosi dan mengikuti beberapa event untuk memotivasi para pelaku UMKM untuk terus berkembang.

Salah satu masalah yang harus dihadapi UMKM agar mampu bersaing pada pangsa pasar yang lebih luas adalah dalam hal mememasarkan produknya dengan label yang lebih menarik. Label adalah bagian dari atribut produk. Label adalah suatu tanda baik berupa tulisan, gambar atau bentuk pernyataan lain yang disertakan pada wadah atau pembungkus sebagai yang memuat informasi tentang produk yang ada di dalamnya sebagai keterangan/ penjelasan dari produk yang dikemas (Kotler, 2000). Selain itu label juga merupakan pemberian informasi tentang produk baik komposisi produk, kandungan gizi, merek, khasiat atau manfaat produk, tanggal kedaluwarsa dll.

Pemberian informasi pada produk yang tertera pada label harus ada unsur kejujuran dari pengusaha atas berbagai informasi yang sesuai dengan kondisi produk. Atribut produk merupakan hal terpenting yang harus dikelola agar dapat mempertahankan dan merebut pangsa pasar yang lebih besar serta menghasilkan keuntungan dimasa yang akan datang.

Menurut Widiyatno (2012) dan juga Arifiana dkk (2013) menyatakan bahwa label yang merupakan bagian dari atribut produk mempengaruhi konsumen di dalam memutuskan pembeliannya

Pada umumnya, para pelaku Usaha Kecil dan Menengah (UMKM) kurang menyadari pentingnya labeling produk mereka, padahal label yang menarik itu mampu mendatangkan 
nilai lebih pada produk yang mereka jual. Dengan belum diperhatikannya labeling pada produk tersebut, mengakibatkan produk yang sebenarnya memiliki nilai tinggi dan berkualitas menjadi kurang bernilai dan tidak mempunyai daya saing untuk pasar global.

Di Kelurahan Tanjung terdapat 28 UMKM khususnya untuk jenis usaha makanan ringan (data statistik Kelurahan Tanjung).

Sebagian besar pemilik usaha tersebut sudah memulai usahanya bertahun-tahun yang lalu, namun keterbatasan pengetahuan dan informasi tentang labeling produk menjadi salah satu kendala dalam memasarkan produknya dalam jangkauan yang lebih luas (data Kecamatan Tanjung). Mereka memasarkan produk mereka dengan label seadanya dan pangsa pasar yang hanya terbatas berdasarkan pelanggan tetap saja.

Berdasarkan permasalahan di atas, Ipteks bagi Masyarakat ini diharapkan dapat menjadi salah satu sarana peningkatan keahlian para pelaku sentra industri makanan ringan di Kelurahan Tanjung dalam membuat desain label produk makanan mereka, sehingga produk tersebut dapat bernilai tinggi dan dapat merambah pasar global serta mampu meningkatkan kapasitas penjualan.

\section{METODE PENGABDIAN PADA MASYARAKAT}

Berdasarkan data mengenai permasalahan yang dialami kelompok mitra di atas, maka permasalahan tersebut haruslah dapat segera diatasi. Sesuai dengan latar belakang yang dimiliki oleh tim pengabdi, yaitu ekonomi, tim pengabdi ingin mencoba menawarkan solusi terhadap permasalahan yang ada pelatihan desain label dan kemasan. Adapun alur rencana kegiatan IbM yang dilaksanakan adalah sebagai berikut:

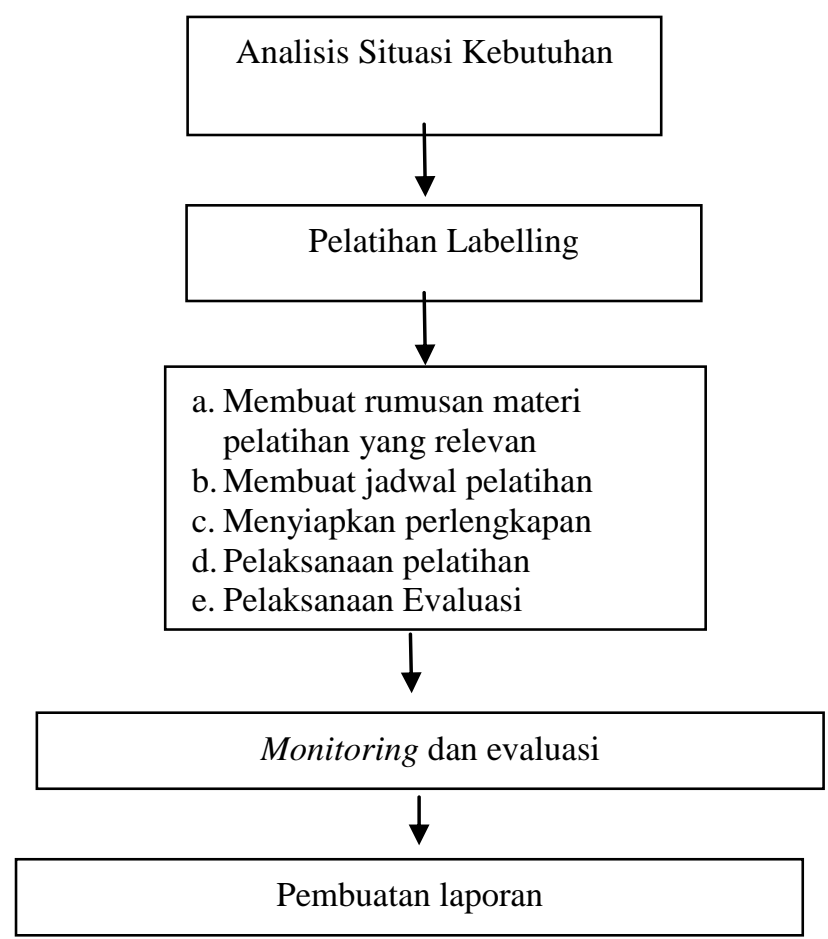

Gambar 1. Alur Program Kegiatan IbM

\section{HASIL DAN PEMBAHASAN}

IbM Pelatihan Desain Label Makanan Olahan pada Sentra Makanan Kecil ${ }^{1}$ telah dilaksanakan pada hari Kamis, 15 Desember 2016 di Balai Kelurahan Tanjung, Acara pelatihan ini menggunakan metode ceramah, dan tanya jawab peserta. Adapun susunan acara yang telah terlaksanan pada kegiatan ini dijelaskan pada tabel 1 berikut : 
Tabel 1. Jadwal Kegiatan IbM

\begin{tabular}{|c|c|c|}
\hline WAKTU & ACARA & KETERANGAN \\
\hline $08.00-08.30$ & Registrasi peserta & Tim \\
\hline $08.30-08.45$ & Pembukaan & $\mathrm{MC}$ \\
\hline $08.45-09.00$ & Sambutan Kepala Kelurahan Tanjung & Tarwono, S.H. \\
\hline $09.00-09.45$ & $\begin{array}{l}\text { Strategi pelabelan produk kemasan makanan } \\
\text { dan minuman yang baik dan menarik }\end{array}$ & $\begin{array}{lll}\text { Herni } & \text { Justiana } & \text { Astuti, } \\
\text { Ph.D } & \end{array}$ \\
\hline $09.45-10.30$ & $\begin{array}{l}\text { Desain kemasan pelabelan makanan yang baik } \\
\text { dan menarik }\end{array}$ & Fatmah Bagis, M.Si. $^{2}$ \\
\hline $10.30-11.15$ & $\begin{array}{l}\text { Desain pelabelan produk minuman yang baik } \\
\text { dan menarik (peluasan produk) }\end{array}$ & Maharani R, M.M. $^{2}$ \\
\hline $11.15-11.45$ & $\begin{array}{l}\text { Pemaparan contoh produk kewirausahaan } \\
\text { mahasiswa }\end{array}$ & Mahasiswa FEB 2 orang \\
\hline $11.45-12.15$ & Diskusi dan tanya - jawab & Tim \\
\hline $12.15-12.25$ & Pemberian kenang-kenangan dan doorpize & $\begin{array}{l}\text { - } \text { Tarwono, S.H. } \\
\text { - } \text { Herni Justiana Astuti, } \\
\text { Ph.D }\end{array}$ \\
\hline $12.25-12.30$ & Penutupan & $\mathrm{MC}$ \\
\hline
\end{tabular}

Waktu pelaksanaan yang semula dalam undangan tertulis pukul 08.00 ternyata baru dapat dilaksanakan pada pukul 09.00 dan berakhir sekitar pukul 12.30. Peserta yang hadir adalah kelompok mitra dari sentra makanan dan minuman olahan di Kelurahan Tanjung sebanyak 20 orang dari 28 undangan. Kelompok mitra sangat antusias terhadap pelatihan ini, hal ini dibuktikan dengan semangatnya kelompok mitra melakukan sharing dengan tim pengabdi.

Di akhir materi juga terdapat 2 mahasiswa manajemen fakultas ekonomi dan bisnis Universitas Muhammadiyah Purwokerto yang memaparkan hasil produk dari proyek kewirausahaan yang sudah diberi label dan kemasan yang menarik. Hasilnya adalah tumbuhnya semangat para mitra untuk melakukan inovasi terhadap desain label dan kemasan untuk dapat menambah nilai ekonomis dari produk kelompok mitra serta meningkatkan volume penjualan. Sesuai dengan kegiatan yang telah dilaksanakan, luaran yang dihasilkan dari kegiatan ini adalah meningkatnya pengetahuan kelompok mitra tentang cara dan pengaturan pelabelan serta evaluasi desain label mitra yang sudah ada.

\section{IV.KESIMPULAN DAN SARAN}

Kegiatan pelatihan desain label ini mampu meningkatkan semangat para pelaku UMKM di Kelurahan Tanjung untuk memperbaiki desain label produk mereka sehingga dapat meningkatkan nilai ekonomis produk serta berdampak pada meningkatnya volume penjualan dan memaksimalkan laba usahanya.

Selain itu, kegiatan IbM ini juga mempu meningkatkan partisipasi dosen dan mahasiswa Universitas Muhammadiyah Purwokerto dalam kegiatan pemberdayaan masyarakat. Adapun saran untuk kegiatan selanjutnya dari kegiatan pengabdian masyarakat ini adalah perlu diadakan kegiatan sejenis dengan peserta yang lebih, yang tidak hanya melibatkan para pelaku UMKM saja di Kelurahan Tanjung, namun juga kelompok PKK dan dengan diadakan pelatihan lanjutan untuk mendapatkan PIRT.

\section{DAFTAR PUSTAKA}

Arifiana, Windya Eka., Kumadji, Srikandi., dan Fanani. Dahlan. 2013. Pengaruh Atribut Produk Terhadap Keputusan Pembelian. Jurnal Administrasi Bisnis (JAB)|Vol. 1 No. 2: 231-240

Kotler, Philip. 2010. Marketing Management; The Millenium Edition. Prentice Hall. USA 
Jurnal Manajemen dan Bisnis MEDIA EKONOMI Volume XVII, NO. 2 Juli 2017

Triyono, A. 2012. Modul Pengemasan Produk Makanan. Kumpulan Modul Pelatihan. UPT B2PTTG-LIPI Subang.

UU Republik Indonesia Nomor 7 Tahun 1996 tentang Pangan

Widiyatno, Bayu. 2012. Pengaruh Artibut Produk Terhadap Proses Keputusan Pembelian Studi Kasus Konsumen Pada Sentra Industri Jeans Di Kecamatan Ulujami Kabupaten Pemalang. Management Analysis Journal. 1 (2): 6-10

www. dindukcapil.banyumaskab.go.id 